\title{
Features of respiratory support during laparoscopic correction of inguinal hernias in children
}

\author{
Volodymyr Mishchuk ${ }^{1}$, Orest Lerchuk², Andriy Dvorakevych ${ }^{3}$, Volodymyr Khomyak $^{4}$ \\ ${ }^{1}$ Department of Anestesiology and Intesive Care, Lviv Regional Children's Hospital “Ohmatdyt”, Lviv, Ukraine \\ ${ }^{2}$ Department of Surgery No 3, Lviv Regional Clinical Hospital, Lviv, Ukraine \\ ${ }^{3}$ Department of Surgery, Lviv Regional Children's Hospital “Ohmatdyt”, Lviv, Ukraine \\ ${ }^{4}$ Department of Surgery No 1, Danylo Halytsky Lviv National Medical University, Lviv, Ukraine
}

Videosurgery Miniinv 2016; 11 (2): 55-59

DOI: $10.5114 /$ wiitm.2016.59837

\begin{abstract}
Introduction: The objectives were to study the changes in the mechanics of respiration in children undergoing surgery depending on the value of intra-abdominal pressure (IAP) during laparoscopic procedures, and to compare the effects of different mechanical ventilation modes - pressure controlled (PCV) and volume controlled (VCV) ventilation - on the mechanics of respiration considering carboxyperitoneum conditions (CP).

Aim: To study the changes in the mechanics of respiration in operated children depending on the value of intra-abdominal pressure during laparoscopic procedures.

Material and methods: Fifty-two children aged 1-12 years undergoing laparoscopic surgery on inguinal hernias were randomly allocated to receive mechanical ventilation using either VCV $(n=24)$ or PCV $(n=28)$ mode. Respiratory mechanics were measured before application of carboxyperitoneum (initial data) and after the gas had been pumped into the abdominal cavity, at the following intra-abdominal pressure values: $6 \mathrm{~mm} \mathrm{Hg}, 8 \mathrm{~mm} \mathrm{Hg}, 10 \mathrm{~mm} \mathrm{Hg}$, $12 \mathrm{~mm} \mathrm{Hg}, 14 \mathrm{~mm} \mathrm{Hg}$.

Results: Elevation of intra-abdominal pressure due to carboxyperitoneum conditions had a negative effect on the mechanics of respiration. Changes in the respiratory mechanics were restrictive in nature in both groups. The patients who were receiving pressure controlled ventilation showed a decrease in tidal volume, exhaled minute volume, and dynamic lung compliance, which affected the gas exchange at intra-abdominal pressure values $\geq 12 \mathrm{~mm} \mathrm{Hg}$. Patients who were receiving volume controlled ventilation showed an increase in peak inspiratory pressure and mean airway pressure and a decrease in dynamic lung compliance in response to higher intra-abdominal pressure. A significant increase of concentration of exhaled carbon dioxide (etCO $\left.\mathrm{C}_{2}\right)$ was registered at IAP $\geq 12 \mathrm{~mm} \mathrm{Hg}$.

Conclusions: Application of carboxyperitoneum causes increased intra-abdominal pressure and restrictive disorders in respiratory mechanics. Intra-abdominal pressure readings within 8-12 $\mathrm{mm} \mathrm{Hg}$ allow laparoscopic procedures to be performed without significant gas exchange disorders in children older than 1 year.
\end{abstract}

Key words: pneumoperitoneum, respiratory mechanics.

\section{Introduction}

Laparoscopic surgery is becoming more and more popular among pediatric surgeons. This is due to the method being minimally traumatic, with multifold possibilities for diagnostics and determination of further tactics of surgical treatment, decrease of peritoneal adhesion risk, and good cosmetic results.

\footnotetext{
Address for correspondence

Orest Lerchuk, Lviv Regional Clinical Hospital, 7 Chernigivska St, 79010 Lviv, Ukraine, phone: 380503706472,

e-mail: lerchuk.orest@gmail.com
} 
The cost of treatment also decreases because of shorter terms of in-hospital treatment, less need for post-operational analgesia, etc [1].

Still, in connection with the introduction of this method of treatment, an anesthesiologist, especially a pediatric one, faces a range of specific problems connected with support of the organism's vital functions during the surgery [1].

Gas being pumped into the abdominal cavity proportionally raises the pressure inside it, which results in compression of the inferior vena cava and aorta. In particular, under the conditions of intra-abdominal pressure (IAP) of $14 \mathrm{~mm} \mathrm{Hg}$ in adults the compression of the inferior vena cava causes the decrease of venous inflow by $20 \%$. Kidney blood flow is also in direct correlation with IAP. Under the conditions of IAP of $20-25 \mathrm{~mm} \mathrm{Hg}$, used in adults during gynecological surgery, the decrease of renal flow and glomerular filtration can cause damage of kidney parenchyma [2]. Changes in the arterial system are characterized by the increase of peripheral vascular resistance as a result of squeezing of abdominal cavity arterial vessels, and activation of vasoactive substances (of the renin-angiotensin system), caused by reduction of kidney flow. As a result, the heart works in conditions of increased afterload and decreased preload. The main compensatory mechanism of cardiac output increase is the development of tachycardia [3].

In children the fluctuation of hemodynamics depends not only on the IAP value, but also on age. Sakka et al. performed transesophageal echocardiography (TEE) and hemodynamic assessment during laparoscopic herniotomies in young children at two different levels of IAP, 6 and $12 \mathrm{~mm} \mathrm{Hg}$. It was found that after the rise of IAP to $12 \mathrm{~mm} \mathrm{Hg}$ the cardiac index $(\mathrm{Cl})$ decreased significantly. The following decrease of IAP to $6 \mathrm{~mm} \mathrm{Hg}$ brought the $\mathrm{Cl}$ back to the initial level [4].

The influence of a high level of IAP on the respiratory system is also very important. This can be explained by the elevation of the diaphragm and restriction of its mobility. As a result, lung compliance decreases, macro- and microatelectases appear in parts of lungs, functional residual lung capacity decreases, ventilation-perfusion problems progress, pulmonary bypass increases, and hypoxemia, hypoventilation, hypercapnia and respiratory acidosis develop [4, 5].

It should be noted that modern medical literature offers wide coverage of problems of anesthe- siological support in adults during laparoscopies. As far as children are concerned, these aspects are not covered sufficiently; namely, safe IAP levels as well as its influence on hemodynamics and breathing in children of different ages are not defined.

\section{Aim}

The objectives were to study the changes in the mechanics of respiration in children depending on the value of intra-abdominal pressure during laparoscopic procedures on inguinal hernias, and to compare the effects of different mechanical ventilation modes - pressure controlled (PCV) and volume controlled (VCV) ventilation - on the mechanics of respiration considering carboxyperitoneum conditions.

\section{Material and methods}

Fifty-two children aged 1-12 years undergoing laparoscopic surgery on inguinal hernias were randomly allocated to receive mechanical ventilation using either VCV $(n=24)$ or PCV $(n=28)$ mode. The study did not include children with respiratory and cardio-vascular system chronic diseases. According to the ASA scale, 44 patients were rated as ASA I and 8 as ASA II.

Anesthesiological support was performed by means of combined intravenous general anesthesia with myoplegia and trachea intubation. Mechanical ventilation (MV) and breathing mechanics monitoring was performed using "Leon" (Germany) anesthesia machines.

In both groups tidal volume (TV) and exhaled minute ventilation (EMV) were set within $6-7 \mathrm{ml} / \mathrm{kg}$ and $150-200 \mathrm{ml} / \mathrm{kg} / \mathrm{min}$ for achieving initial etCO $\mathrm{C}_{2}$ within 30-35 mm Hg. Ratio of inhale to exhale phase was $1: 1.5, \mathrm{FiO}_{2}-60 \%$. Lung gas exchange function was monitored by a GE Datex Ohmeda Cardiocap 5 monitor (USA). In patients of both groups peak inspiratory pressure (PIP), mean airway pressure (Pmean), $\mathrm{TV}$, and dynamic compliance (Cdyn) were registered as well as saturation $\left(\mathrm{SaO}_{2}\right)$, and et $\mathrm{CO}_{2}$ depending on the IAP value. The IAP was measured by the manometer in laparoscopic equipment. Respiratory mechanics values were measured before application of carboxyperitoneum (initial data) and after the gas had been pumped into the abdominal cavity, at the following intra-abdominal pressure values: $6 \mathrm{~mm}$ $\mathrm{Hg}, 8 \mathrm{~mm} \mathrm{Hg}, 10 \mathrm{~mm} \mathrm{Hg}, 12 \mathrm{~mm} \mathrm{Hg}, 14 \mathrm{~mm} \mathrm{Hg}$. Then ventilation parameters correction was carried 
out with the aim of achieving satisfactory minute lung ventilation, oxygenation and normocapnia. The main surgery stage was performed at IAP values of 8-12 $\mathrm{mm} \mathrm{Hg}$.

The planned research was examined by the bioethics commission of Lviv children's clinical hospital "Ohmatdyt". It was determined that the research provides measures concerning patients' health safety, observing their rights, human dignity and moral and ethical norms according to the principles of the Human Rights Declaration of Helsinki, Council of Europe Convention on Human Rights and Biomedicine and relevant laws of Ukraine. In each separate case, parents' informed written consent for including their child in the research was received.

\section{Results}

The obtained data show that elevation of intra-abdominal pressure due to carboxyperitoneum conditions had a negative effect on the mechanics of respiration. The main characteristic, showing the restrictive type of respiratory mechanics aggravation, was a considerable decrease of lung compliance in response to higher intra-abdominal pressure (Figure 1).

The patients who were receiving pressure controlled ventilation showed a decrease in TV, EMV, and Cdyn, which affected the gas exchange at the following intra-abdominal pressure value of $\geq 12 \mathrm{~mm} \mathrm{Hg}$ (Table I).

In group I patients procedures were performed at IAP values of $8-12 \mathrm{~mm} \mathrm{Hg}$. Ventilation parameters correction was carried out by means of gradual increase of PIP until the TV level of $6-7 \mathrm{ml} / \mathrm{kg}$ and breathing rate reaching normocapnia. The EMV

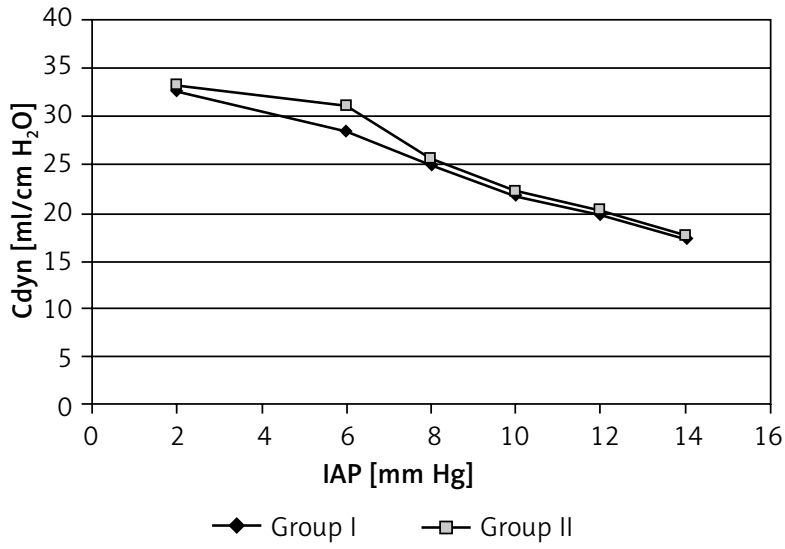

Figure 1. Change of lung compliance depending on intra-abdominal pressure value

was increased by $34.8 \pm 11.6 \mathrm{ml} / \mathrm{kg} / \mathrm{min}$ (18.6\%). The maximum PIP value was $20.0 \pm 2.4 \mathrm{~cm} \mathrm{H}_{2} \mathrm{O}$.

Group II patients, who were receiving volume controlled ventilation, showed increases in PIP and Pmean and a decrease in Cdyn in response to higher intra-abdominal pressure. A significant increase of concentration of exhaled carbon dioxide was registered at IAP $\geq 12 \mathrm{~mm} \mathrm{Hg}$ (Table II).

In group II patients procedures were performed at IAP values of 8-12 $\mathrm{mm} \mathrm{Hg}$. Ventilation parameters correction was carried out by means of increasing breath rate for reaching normocapnia. Normocapnia was reached by increasing minute ventilation by $38.1 \pm 12.2 \mathrm{ml} / \mathrm{kg} / \mathrm{min}$. Satisfactory TV was reached by higher PIP $\left(23.6 \pm 4.5 \mathrm{~cm} \mathrm{H}_{2} \mathrm{O}\right)$ in comparison with patients with pressure controlled ventilation.

Analyzing the findings concerning the influence of IAP on pulmonary mechanics in children, we can make the conclusion that, unlike adults, children develop problems with ventilation and gas exchange

Table I. Dynamics of respiratory mechanics and gas exchange values depending on IAP value in patients who were receiving pressure controlled ventilation

\begin{tabular}{|c|c|c|c|c|c|c|c|}
\hline IAP & $\begin{array}{c}\mathrm{PIP} \\
{\left[\mathrm{cm} \mathrm{H} \mathrm{H}_{2} \mathrm{O}\right]}\end{array}$ & $\begin{array}{c}\text { Pmean } \\
{\left[\mathrm{cm} \mathrm{H}_{2} \mathrm{O}\right]}\end{array}$ & $\begin{array}{c}\text { TV } \\
{[\mathrm{ml} / \mathrm{kg}]}\end{array}$ & $\begin{array}{c}\text { EMV } \\
{[\mathrm{ml} / \mathrm{kg} / \mathrm{min}]}\end{array}$ & $\begin{array}{c}\text { Cdyn } \\
{\left[\mathrm{ml} / \mathrm{cm} \mathrm{H}_{2} \mathrm{O}\right]}\end{array}$ & $\begin{array}{c}\mathrm{SaO}_{2} \\
(\%)\end{array}$ & $\begin{array}{c}\mathrm{etCO}_{2} \\
{[\mathrm{~mm} \mathrm{Hg}]}\end{array}$ \\
\hline Initial data & $16.4 \pm 2.5$ & $8.1 \pm 1.6$ & $7.1 \pm 2.5$ & $186.3 \pm 21.2$ & $32.7 \pm 6.8$ & $99.1 \pm 7.7$ & $33.2 \pm 4.4$ \\
\hline $6 \mathrm{~mm} \mathrm{Hg}$ & $16.4 \pm 2.5$ & $8.3 \pm 1.7$ & $6.4 \pm 1.8$ & $165.1 \pm 18.9$ & $31.1 \pm 6.0$ & $99.1 \pm 7.7$ & $33.7 \pm 4.6$ \\
\hline $8 \mathrm{~mm} \mathrm{Hg}$ & $16.4 \pm 2.5$ & $10.4 \pm 2.1$ & $5.5 \pm 1.5$ & $160.3 \pm 18.3$ & $24.9 \pm 5.2$ & $98.5 \pm 7.6$ & $35.2 \pm 5.2$ \\
\hline 10 mm Hg & $16.4 \pm 2.5$ & $11.2 \pm 2.3$ & $4.1 \pm 1.1$ & $144.6 \pm 16.7$ & $21.6 \pm 4.8$ & $98.4 \pm 7.6$ & $39.3 \pm 6.3$ \\
\hline $12 \mathrm{~mm} \mathrm{Hg}$ & $16.4 \pm 2.5$ & $11.3 \pm 2.5$ & $3.8 \pm 0.9$ & $127.2 \pm 15.1^{\star}$ & $19.7 \pm 4.4$ & $98.4 \pm 7.6$ & $42.5 \pm 6.7$ \\
\hline 14 mm Hg & $16.4 \pm 2.5$ & $11.5 \pm 2.6$ & $3.6 \pm 0.8$ & $111.7 \pm 13.5^{\star}$ & $17.2 \pm 3.5^{\star}$ & $98.0 \pm 7.5$ & $47.2 \pm 7.4$ \\
\hline
\end{tabular}


Table II. Dynamics of respiratory mechanics and gas exchange values depending on IAP value in patients who were receiving volume controlled ventilation

\begin{tabular}{|lccccccc|}
\hline IAP & $\begin{array}{c}\mathrm{PIP} \\
{\left[\mathrm{cm} \mathrm{H} \mathrm{H}_{2} \mathrm{O}\right]}\end{array}$ & $\begin{array}{c}\text { Pmean } \\
{[\mathrm{cm} \mathrm{H} \mathrm{O}]}\end{array}$ & $\begin{array}{c}\mathrm{TV} \\
{[\mathrm{ml} / \mathrm{kg}]}\end{array}$ & $\begin{array}{c}\mathrm{EMV} \\
{[\mathrm{ml} / \mathrm{kg} / \mathrm{min}]}\end{array}$ & $\begin{array}{c}\mathrm{Cdyn} \\
{\left[\mathrm{ml} / \mathrm{cm} \mathrm{H}_{2} \mathrm{O}\right]}\end{array}$ & $\begin{array}{c}\mathrm{SaO}_{2} \\
(\%)\end{array}$ & $\begin{array}{c}\text { etCO } \\
{[\mathrm{mm} \mathrm{Hg}]}\end{array}$ \\
\hline Initial data & $16.1 \pm 2.4$ & $8.2 \pm 1.4$ & $7.6 \pm 1.6$ & $180.5 \pm 14.2$ & $33.4 \pm 7.5$ & $98.7 \pm 7.6$ & $33.6 \pm 4.9$ \\
\hline $6 \mathrm{~mm} \mathrm{Hg}$ & $17.2 \pm 2.8$ & $8.6 \pm 1.6$ & $7.5 \pm 1.5$ & $180.5 \pm 14.2$ & $29.4 \pm 5.1$ & $98.7 \pm 7.6$ & $35.2 \pm 5.1$ \\
\hline $8 \mathrm{~mm} \mathrm{Hg}$ & $18.4 \pm 3.2$ & $9.8 \pm 2.2$ & $7.3 \pm 1.5$ & $175.2 \pm 14.1$ & $25.6 \pm 4.4$ & $98.6 \pm 7.6$ & $38.1 \pm 5.8$ \\
\hline $10 \mathrm{~mm} \mathrm{Hg}$ & $18.9 \pm 3.6$ & $10.6 \pm 2.4$ & $7.1 \pm 1.4$ & $175.2 \pm 14.1$ & $22.3 \pm 3.2$ & $98.6 \pm 7.6$ & $38.8 \pm 6.1$ \\
\hline $12 \mathrm{~mm} \mathrm{Hg}$ & $21.1 \pm 4.1$ & $11.6 \pm 3.8$ & $7.1 \pm 1.4$ & $172.2 \pm 13.4$ & $20.3 \pm 2.8$ & $98.5 \pm 7.6$ & $42.7 \pm 6.6$ \\
\hline $14 \mathrm{~mm} \mathrm{Hg}$ & $23.6 \pm 4.5$ & $12.9 \pm 4.2$ & $7.0 \pm 1.2$ & $168 \pm 12.7$ & $17.6 \pm 2.3^{*}$ & $98.2 \pm 7.4$ & $45.3 \pm 7.1$ \\
\hline${ }_{*}^{*}<<0.05$ (statistical significance in relation to initial data). & & & & & &
\end{tabular}

at lower IAP values. Problems are statistically significant at IAP values of $14 \mathrm{~mm} \mathrm{Hg}$. For adequate anesthetic protection in conditions of pneumoperitoneum one needs large scale monitoring of respiratory mechanics, capnography as well as coordinated work of an anesthesiologist and the surgical team with the aim of supporting a safe level of IAP. Our experience shows that laparoscopic procedures in children can be effectively carried out at IAP of 8-12 mm Hg, which minimizes the negative influence of high IAP on gas exchange and hemodynamics.

\section{Discussion}

Today there are not a lot of studies on the use of different modes of mechanical ventilation during laparoscopic surgery in children. This issue is far better studied in adults. Similar results were obtained in a study of children who underwent laparoscopic appendectomy by Kim et al. [6]. Dynamic compliance was significantly higher in the PCV group than in the VCV group, although it was decreased in both groups in response to an increase in intra-abdominal pressure. Peak and mean airway pressures were increased in both PCV and VCV groups in response to an increase in IAP, but mean airway pressure was higher in the PCV group compared with that in the VCV group. There were no differences in other ventilatory parameters or oxygen saturation.

Tyagi et al. analyzed the effect of modes VCV and PCV on mechanics of breathing during laparoscopic cholecystectomy in adults [7]. Both peak and mean airway pressures in the VCV and PCV groups were similar 5 min after tracheal intubation. However, at both 10 and $30 \mathrm{~min}$ after the start of surgery, the peak airway pressure was significantly decreased and the mean airway pressure was increased in the PCV group, compared with the VCV group. The authors also noted that compliance was significantly higher in the PCV group, but only 5 min after tracheal intubation; after surgery had started there was no difference.

Another study in gynecological laparoscopic surgery compared the effects of VCV with PCV on respiratory mechanics and noninvasive hemodynamic parameters [8]. Sixty ASA I-II women were randomly allocated to the VCV group $(n=30)$ or PCV group $(n=30)$. In the results, VCV was associated with a significant increase in peak airway pressure, plateau pressure, and airway resistance $(p<0.05)$. Compliance was significantly higher in the PCV group $(p<0.05)$. No other significant differences were found between the groups.

In our view, the advantage of the PCV regime in children is related to low lung compliance and the risk of possible loss of respiratory volume in the breathing circuit.

\section{Conclusions}

Application of carboxyperitoneum causes increased intra-abdominal pressure and restrictive disorders in respiratory mechanics. Intra-abdominal pressure readings within $8-12 \mathrm{~mm} \mathrm{Hg}$ allow laparoscopic procedures to be performed without significant gas exchange disorders in children older than 1 year. Increase of IAP > $12 \mathrm{~mm} \mathrm{Hg}$ caused significant decrease of $\mathrm{Cdyn}$ and increase of etCO $\mathrm{C}_{2}$. Respiratory mechanics readings correction in PCV mode allows adequate TV and EMV to be reached at lower PIP and Pmean values in comparison with VCV ventilation. 


\section{Conflict of interest}

The authors declare no conflict of interest.

\section{References}

1. Ahmed A. Laparoscopic surgery in children-anaesthetic considerations. J Pak Med Assoc 2006; 56: 75-9.

2. Schramm P, Engelhard K, Scherhag A, et al. High-intensity transient signals during laparoscopic surgery in children. $\mathrm{Br} J \mathrm{An}$ aesth 2010; 104: 224-7.

3. Sakka SG, Huettemann E, Petrat G, et al. Transoesophageal echocardiographic assessment of haemodynamic changes during laparoscopic herniorrhaphy in small children. $\mathrm{Br}$ J Anaesth 2000; 84: 330-4.

4. Rauh R, Hemmerling TM, Rist M, Jacobi KE. Influence of pneu moperitoneum and body positioning on respiratory system compliance. J Clin Anesth 2001; 13: 361-5.

5. Hazebroek EJ, Haitsma JJ, Lachmann B, Bonjer HJ. Mechanica ventilation with positive end-expiratory pressure preserves arterial oxygenation during prolonged pneumoperitoneum. Surg Endosc 2002; 16: 685-9.

6. Kim JY, Shin CS, Lee KC, et al. Effect of pressure-versus volume-controlled ventilation on the ventilatory and hemodynamic parameters during laparoscopic appendectomy in children: a prospective, randomized study. J Laparoendosc Adv Surg Tech A 2011; 21: 655-8.

7. Tyagi A, Kumar R, Sethi AK, Mohta M. A comparison of pres sure-controlled and volume-controlled ventilation for laparoscopic cholecystectomy. Anaesthesia 2011; 66: 503-8.

8. Ogurlu M, Küçük M, Bilgin F, et al. Pressure controlled vs. volume-controlled ventilation during laparoscopic gynecologic surgery. J Minim Invasive Gynecol 2010; 17: 295-300.

Received: 14.06.2015, accepted: 29.02.2016. 